\title{
Marketing estratégico turístico para la Provincia del Azuay-Ecuador.
}

\section{Strategic tourism marketing for the Province of Azuay. Ecuador.}

Edwin Rene Idrovo Mogrovejo. ${ }^{1}$, Kléber Antonio Luna Altamirano. ${ }^{2}$, Janice Licenia Ordoñez Parra. ${ }^{3}$ \& Mónica Alexandra Lituma Yascaribay. ${ }^{4}$

\section{DOI: https://doi.org/10.33262/visionariodigital.v3i2.408}

\section{Resumen.}

El sector turístico ha evidenciado un exponencial crecimiento en el Ecuador, específicamente en la provincia del Azuay, por lo que se percibe como una gran oportunidad para lograr un mayor dinamismo económico y social de dicho territorio. En este sentido, el Gobierno Autónomo Descentralizado Municipal del cantón Nabón se ha planteado alternativas para obtener ventajas competitivas que apoyen al turismo con estándares de calidad. Es por ello que, esta investigación tiene como propósito proponer un plan de marketing estratégico para la promoción y difusión del turismo en el Municipio Nabón. Esta investigación es de tipo descriptiva, con un diseño no experimental de campo. Se realizó una revisión documental en cuanto al marketing turístico. La fuente de información estuvo conformada por los registros de datos históricos de visitantes al cantón a través de la Unidad de Turismo del GAD Municipal Nabón y se aplicó un instrumento de recolección de información aplicado a 150 informantes de la zona. Finalmente, los resultados indican que se debe capacitar al talento humano perteneciente al GAD Municipal del cantón Nabón en cuanto a las actividades que se deben realizar para el desarrollo turístico en la zona, así mismo se deben aplicar estrategias desde una perspectiva corporativa, comunicacional, competitiva, funcional y de posicionamiento turístico, las cuales, contribuirán al cumplimiento de las metas estratégicas referentes al desarrollo turístico en el cantón Nabón, por cuanto se propone un plan de marketing que

\footnotetext{
1 Universidad Católica de Cuenca, Maestrante en Administración de Empresas, Cuenca, Ecuador. eridrovom478@psg.ucacue.edu.ec

2 Universidad Católica de Cuenca, Unidad Académica de Administración, Cuenca, Ecuador. klunaa@ucacue.edu.ec

3 Universidad Católica de Cuenca, Unidad Académica de Administración, Cuenca, Ecuador. jordonezp@ucacue.edu.ec

4 Universidad Católica de Cuenca, Unidad Académica de Administración, Cuenca, Ecuador. mliyumay@ucacue.edu.ec
} 
permita cumplir con las expectativas turísticas. Se concluye que el plan de marketing lograra hacer que la zona de la provincia aumente de la calidad de vida de la comunidad.

Palabras clave: Marketing, turismo, estrategias de marketing, Ecuador.

\begin{abstract}
The tourism sector has shown exponential growth in Ecuador, specifically in the province of Azuay, which is perceived as a great opportunity to achieve greater economic and social dynamism of that territory. In this sense, the Municipal Decentralized Autonomous Government of the canton Nabón has raised alternatives to obtain competitive advantages that support tourism with quality standards. Therefore, this research aims to propose a strategic marketing plan for the promotion and dissemination of tourism in the Municipality of Nabón. This research is of a descriptive type, with a non-experimental field design. A documentary review was carried out on tourism marketing. The information source consisted of historical data records of visitors to the canton through the Tourism Unit of the Nabón Municipal GAD and applied a data collection tool applied to 150 informants in the area. Finally, the results indicate that human talent belonging to the Municipal GAD of Nabón canton should be trained in the activities that should be carried out for tourism development in the area, as well as strategies should be applied from a corporate perspective, communicational, competitive, functional and tourist positioning, which will contribute to the achievement of strategic goals relating to tourism development in Nabón canton, as a marketing plan is proposed to meet tourism expectations. It is concluded that the marketing plan will succeed in making the area of the province increase the quality of life of the community.
\end{abstract}

Abstract: Marketing, tourism, marketing strategies, Ecuador

\title{
Introducción.
}

El cantón Nabón se encuentra en la provincia del Azuay a 73 kilómetros de la ciudad de Cuenca, tiene una extensión de $945,2 \mathrm{~km} 2$, se encuentra a una altitud de $2680 \mathrm{msnm}$, tiene una temperatura que oscila entre $\operatorname{los} 8^{\circ}$ y $20^{\circ}$ centígrados, tiene una población de 18.000 habitantes de los cuales el $35 \%$ es indígena.

El Gobierno Autónomo Descentralizado Municipal Nabón, dentro su organización cuenta con procesos agregados de valor como la Dirección de Gestión de Servicios y Comercialización, cuya misión es "Brindar servicios a la comunidad que apoyen al principio constitucional del buen vivir". Su directos es el responsable de brindar un beneficio y servicio a la comunidad generan ingresos y atraen turistas.

El principal problema para el cantón Nabón, es atraer a visitantes nacionales e internacionales, a pesar de contar con muchos atractivos tales como: la singularidad de sus paisajes con grandes cañones naturales, lugares arqueológicos, emprendimientos productivos, botánicos y deportivos. Sin embargo, existen otros cantones que compiten, 
tales como Guacaleo, Paute, Santa Isabel, que, a más de encontrarse en sectores estratégicos, cuentan con un clima tropical.

En este sentido, el crecimiento en el número de destinos turísticos provoca un importante incremento de la competencia, por lo que se hace necesario profundizar en cuales son los factores que expliquen su competitividad. Por cuanto se puede establecer un Plan de Marketing Estratégico, de forma que ello permita una mejor comprensión para establecer las bases y estrategias encaminadas a alcanzar un desarrollo turístico sostenible y competitivo.

Es importante destacar que la presente investigación se encuentra estrechamente relacionada con los objetivos, políticas y lineamientos estratégicos del Plan Nacional de Desarrollo Toda una Vida 2017-2021 del Gobierno de Ecuador. En este sentido se plantean a continuación los objetivos y políticas a implementar en dicho plan.

Tabla 1. Objetivos y Políticas Toda una vida

\begin{tabular}{|c|c|c|}
\hline Eje & Objetivos & Políticas \\
\hline $\begin{array}{l}\text { 1. Derechos para todos } \\
\text { durante toda la vida. }\end{array}$ & $\begin{array}{l}\text { Garantizar una vida digna con } \\
\text { Iguales oportunidades para } \\
\text { todas las personas }\end{array}$ & $\begin{array}{l}\text { Promover el uso y el disfrute de } \\
\text { un habitat seguro, que permita el } \\
\text { acceso equitativo a los espacios } \\
\text { públicos con enfoque inclusivo, } \\
\text { Promover la protección de los } \\
\text { derechos de usuarios y } \\
\text { consumidores de bienes y } \\
\text { senvicios. }\end{array}$ \\
\hline $\begin{array}{l}\text { 2. Economia al servicio } \\
\text { de la sociedad. }\end{array}$ & $\begin{array}{l}\text { Consolidar la sostenibilidad del } \\
\text { sistema económico, social y } \\
\text { solidario y afi-arzar la } \\
\text { dolarización. } \\
\text { Impulsar la productividad y } \\
\text { competitividad para el } \\
\text { crecimiento económico } \\
\text { sostenible, de manera } \\
\text { redistributiva y solidaria }\end{array}$ & $\begin{array}{l}\text { Promover el rescate, } \\
\text { reconocimiento y protección del } \\
\text { patrimonio cultural tangible e } \\
\text { intangible, saberes ancestrales, } \\
\text { cosmovisiones y dinámicas } \\
\text { culturales. }\end{array}$ \\
\hline
\end{tabular}

Fuente: Secretaria Nacional de Planificación y Desarrollo. Ecuador 2017

En virtud de ello, se planteará una propuesta que se enmarque y este bajo los lineamientos del Gobierno autónomo Descentralizado Municipal Nabón, y de esta forma incrementar el turismo en el cantón, bajo los criterios de beneficio social y dinamismo de la economía local, fortaleciendo a microempresas y emprendimientos locales, fomentando la productividad y el desarrollo de la región.

\section{El marketing como herramienta para la promoción y difusión del turismo.}

El enigma del marketing es que es una de las actividades más antiguas del hombre y, sin embargo, es considerada como la más reciente de las disciplinas empresariales. 
Para Kotler (1992) el concepto de marketing no es una definición sobre lo que es y hace el marketing. Se trata de una forma de pensar, una filosofía de dirección, sobre cómo debe entenderse la relación de intercambio de los productos/servicios de una organización con el mercado. La forma de concebir la actividad de intercambio ha pasado por orientaciones distintas en su evolución, hasta llegar al concepto actual de marketing, en el que se contemplan no sólo las necesidades del individuo sino también, las de la sociedad en general.

Desafortunadamente, el marketing en el verdadero sentido de la palabra, no se aplica con total efectividad en el mundo de los negocios, sin ser excluyente la industria de viajes y turismo. Por supuesto, existen algunas organizaciones de turismo que han adoptado la filosofía del marketing de manera significativamente positiva, pero aun así se considera que estas también siguen siendo la excepción y no la regla (Pinassi, 2012).

En este momento, el turismo es considerado uno de los negocios de más rápido crecimiento y más competitivo del mundo. Cada país y negocio turístico se esfuerza por conseguir más turistas y concentrarse en sus destinos. De ahí que el sector turístico aún necesita establecer un proceso de marketing más que otras cosas, ya que el cliente de esta industria tiene muchas opciones y diferentes motivaciones para viajar (Martínez, 2011). Análogamente, cada año, el número de turistas a nivel mundial va en aumento, y se anticipa estas cifras crecerán más día a día, por lo que, al parecer, las oportunidades en la industria turística son infinitas. Sin embargo, todavía hay muchas empresas de turismo que no logran aprovechar estas posibilidades, pero es precisamente el marketing la herramienta que haría posible lidiar con este tipo de problemas, usando para ello estrategias de promoción y difusión para lograr captar una mayor cantidad de clientes (Carballo, Moreno, León, y Brent, 2015).

Específicamente en el Ecuador, las funciones de marketing relacionadas con la promoción son determinadas mediante los lineamientos establecidos en el Diseño del Plan de Desarrollo de Turismo Sostenible para Ecuador "PLANDETUR 2020" (Consultor Tourism y Leisure, 2007), donde se enfatiza que:

A partir del Plan de Competitividad Turística y del Benchmarking del Turismo Ecuatoriano en los que se plantea la necesidad de contar con un mecanismo eficaz de promoción, un plan de mercadeo y con un sistema de inteligencia de mercados; la promoción del Ecuador ha sido un tema considerado clave tanto en planes regionales como sectoriales, los mismos que coinciden en sus estrategias de búsqueda de mercados objetivos, información profesional y un posicionamiento claro del Ecuador. (p. 14)

Además, el PLANDETUR 2020 determina como política para la conservación y aprovechamiento sostenible del turismo en el Ecuador "impulsar la identificación y promoción de las potencialidades turísticas de las áreas protegidas, los bosques 
protectores, las playas y bahías, nevados y otros recursos escénicos" (Consultor Tourism y Leisure, 2007, p.25).

Es así como se reconoce que "la promoción del turismo constituye una gran oportunidad no solamente por la posibilidad de conservar los recursos naturales del país, sino también porque la afluencia de turistas quienes cubren el pago por entradas aporta al financiamiento necesario para su gestión" (Consultor Tourism y Leisure, 2007, p.51).

El marketing utilizado como herramienta para la comercialización y satisfacción de los clientes se vuelve eficaz en el ámbito turístico, tal como lo mencionan Muñiz y Martínez (2010) quienes plantean que el marketing surge como un mecanismo de gestión empresarial para la comercialización de bienes y servicios y actualmente es utilizado para entes públicos, así como también para potenciar las ofertas turísticas de países, regiones y ciudades, y de esta manera comercializar sus ofertas y ser mejores competidores en el mercado consumidor, dando como resultado relaciones de intercambio comercial entre oferta y demanda.

Asimismo, para tener éxito en el marketing orientado a la industria turística, las organizaciones deben comprender las características únicas que ofrecen sus experiencias turísticas, las motivaciones y comportamientos de los consumidores que viajan y las diferencias fundamentales entre los bienes y servicios de comercialización (Mendes, Augusto, y Gándara, 2013).

Por consiguiente, diferentes entidades gubernamentales deben incidir de manera directa y significativa al desarrollo turístico en la nación ecuatoriana, ya que, específicamente, se sostiene que "el turismo es la base de la economía nacional, por lo que se deben emprender acciones para fomentarlo. Aquí se insiste en la necesidad de la corresponsabilidad de todos los actores en los diferentes niveles de gobierno, así como en el sector público y privado" (Secretaría Nacional de Planificación y Desarrollo, 2017, p. 106).

Esto se corresponde con las políticas emitidas al respecto en cuanto a "posicionar y potenciar a Ecuador (...) fortaleciendo la oferta turística nacional y las industrias culturales; fomentando el turismo receptivo como fuente generadora de divisas y empleo, en un marco de protección del patrimonio natural y cultural" (Secretaría Nacional de Planificación y Desarrollo, 2017, p. 106), lo que generaría a su vez un incremento de la cantidad de empleos relacionados al sector turístico, además del aumento del número de turistas nacionales y extranjeros.

Todo ello hace parte de los ejes estratégicos nacionales en el Ecuador, donde, a través del Plan Nacional Toda una Vida, se establece el planteamiento de propuestas para potenciar "el desarrollo de la oferta turística nacional, el turismo receptivo y comunitario, vinculando los saberes y conocimientos de las comunidades en los procesos turísticos; y 
la promoción de industrias turísticas y culturales" (Secretaría Nacional de Planificación y Desarrollo, 2017, p. 104), mediante la divulgación y promoción de emprendimientos regionales y el turismo comunitario rural, urbano, marino y terrestre, logrando con todo ello la utilización moderada y sostenible de la biodiversidad.

\section{Estrategias de marketing para el desarrollo del turismo}

Desde una perspectiva teórica, los esfuerzos de promoción turística (en términos de asistencia en carreteras, espectáculos, marketing, publicidad y marca, entre otros) tienen como objetivo principal la amplia difusión de información crucial sobre un destino y sus atractivos; todo ello es aún más crucial dado el mundo globalizado y competitivo de hoy; aún más para las economías de países que se encuentran en vías de desarrollo, las cuales presentan diversas dificultades para lograr atraer nuevos visitantes a las principales áreas de generación turística (Kotler y Keller, 2012).

En efecto, el principal objetivo de los gobiernos nacionales o autónomos con respecto al sector turístico, precisamente es la promoción de sus aspectos relevantes, y esto se logra principalmente a través del uso de la publicidad en los medios y las relaciones públicas (González, 2011). Este tipo de organizaciones generalmente conceptualizan la campaña de marketing, diseñan estrategias promocionales e implementan el programa. También participan en el diseño del contenido publicitario, folletos y publicidad en los medios de comunicación, así como en el diseño y mantenimiento de sitios web efectivos y otras publicaciones relacionadas que solo pueden servir para mejorar el resultado de su campaña de marketing.

El establecimiento y mantenimiento de un sitio web es aún más crucial, dado que Internet es, con mucho, el medio más utilizado para planificar viajes y vacaciones en países desarrollados. Además, los esfuerzos de promoción de un país también se pueden realizar a través de exposiciones itinerantes en países donde prevalece el potencial de atracción de turistas, cuyo objetivo principal consiste en presentar una imagen positiva concertada del país y centrarse en las bondades ofrecidas por los diferentes mercados turísticos regionales (Castillo y Castaño, 2015).

En general, se puede afirmar que la mayor parte de los esfuerzos de promoción turística generalmente los realiza el gobierno central o local (a través de asignaciones presupuestarias, además de las medidas fiscales relacionadas con el turismo) a través de instituciones especializadas.

Todo ello lleva a considerar que los gastos promocionales, percibidos como un elemento que afecta los flujos de turismo en un país, constituyen un factor determinante para los mismos, según los hallazgos obtenidos en diversos estudios al respecto (Oliveras, 2015; Cardet, Palao, y González, 2017; Cayo y Apaza, 2017); tales hallazgos tienden a sugerir que la inversión en la promoción de los países y sus regiones como destino turístico, 
resulta beneficiosa en cierta medida, dependiendo de cuánto represente financieramente el valor de la inversión, así como la efectividad de las estrategias de marketing asociadas a dicha inversión.

Kotler y Keller (2012) Plantean la segmentación del mercado turístico, por lo que es posible dividir la secuencia de la creación y entrega de valor en tres fases: La primera, elegir el valor es la "tarea" que debe llevar a cabo el marketing antes de que exista cualquier producto. Los especialistas en marketing deben segmentar el mercado, dirigirse al mercado meta adecuada, y desarrollar el posicionamiento del valor de la oferta. La fórmula "segmentación, direccionamiento, posicionamiento" es la esencia del marketing estratégico (Kotler y Keller, 2012).

La segunda fase es: proveer el valor. El marketing debe determinar las características específicas del producto, su precio y su distribución. La tarea de la tercera fase es: comunicar el valor por medio de la fuerza de ventas, Internet, publicidad y cualquier otra herramienta de comunicación para anunciar y promover el producto. El proceso de entrega de valor se inicia antes de que exista un producto, y continúa durante el desarrollo del mismo y después de su lanzamiento. Cada fase tiene implicaciones en costos (Kotler y Keller, 2012).

En otro orden de ideas, González (2011), plantea que con las estrategias de marketing se trata de llegar a una mayor comprensión con los grupos de interés, por lo tanto, menciona: que dentro de las estrategias de marketing, cada vez toman un mayor protagonismo los grupos de presión que intentan alcanzar a los distintos stakeholders de las organizaciones o proteger unos intereses delimitados de manera fidedigna, genuina y legal.

Para el caso de los gobiernos autónomos del Ecuador, los stakeholders del sector turístico de las regiones del país presentan una situación privilegiada, ya que estos se encuentran favorecidos por las disposiciones emitidas en el COOTAD, quien establece de forma general "como función del gobierno autónomo descentralizado parroquial rural, el fomento a la inversión y el desarrollo económico especialmente de la economía popular y solidaria, en sectores como el turismo, en coordinación con los demás gobiernos autónomos descentralizados" (Gobierno Nacional, 2015, p. 2).

Estos stakeholders, los cuales son fundamentalmente los operadores turísticos, las comunidades regionales, los propios gobiernos autónomos, turistas naciones, extranjeros y demás integrantes de la cadena de valor del sector del turismo, poseen varios beneficios para aumentar la calidad de su nivel de gestión, basado principalmente en aspectos tales como:

- Recibimiento de asistencia técnica para el caso de los prestadores de servicios turísticos por parte de entidades gubernamentales a nivel nacional, provincial, municipal y cantonal, según corresponda. 
- Consolidación de denuncias de turistas expedidas por las diferentes instancias de gobiernos autónomos descentralizados.

- Proporción de información clara y concisa por parte de las autoridades pertinentes a los diferentes grupos de interés.

- Derecho de recibir una promoción precisa y verdadera, sin sobredimensionar el verdadero valor que presentan las ofertas turísticas de las regiones.

- Regulación del desarrollo del sector turístico municipal y cantonal en coordinación con los demás gobiernos autónomos descentralizados, promoviendo especialmente la creación y funcionamiento de organizaciones asociativas y de turismo comunitario, conforme la normativa vigente.

- Impulso de campañas de concienciación ciudadana que generen una cultura sobre la importancia del turismo.

- Fomento de proyectos turísticos regionales impulsado por organizaciones emprendedoras u otras que guarden concordancia con la legislación vigente (Gobierno Nacional, 2015, pp. 6-7).

Tales acciones presuponen un verdadero apoyo a la gestión turística para las regiones menos favorecidas del Ecuador, lo cual debe ser aprovechado por los gobiernos autónomos provinciales, municipales y demás entidades gubernamentales en el marco del desarrollo de las regiones y el país de manera general.

\section{La propuesta de un plan de marketing estratégico}

Con el Plan de Marketing que se propone, se encontraran las condiciones idóneas para reformular una gestión económica con base en el desarrollo y fomento del turismo local, colocando así a la región en el centro de las políticas nacionales e implementando estrategias efectivas para crear una visión estandarizada sobre el turismo y la cultura que tienen lugar en el cantón. Asimismo, el Plan de Marketing es útil para guiar una línea de trabajo con las organizaciones responsables del turismo en el cantón Nabón, mejorando así las políticas en términos de demanda y oferta. Su objetivo principal consiste en proporcionar un marco simple y claro para mejorar las decisiones tomadas en el sector turístico y promover la integración regional.

El Plan de Marketing adopta una novedosa e innovadora perspectiva basada en un método abierto y participativo para compartir estrategias y objetivos que presentan los grupos de interés de la región. El plan de marketing para el cantón Nabón, se corresponde con la figura que se muestra a continuación: 


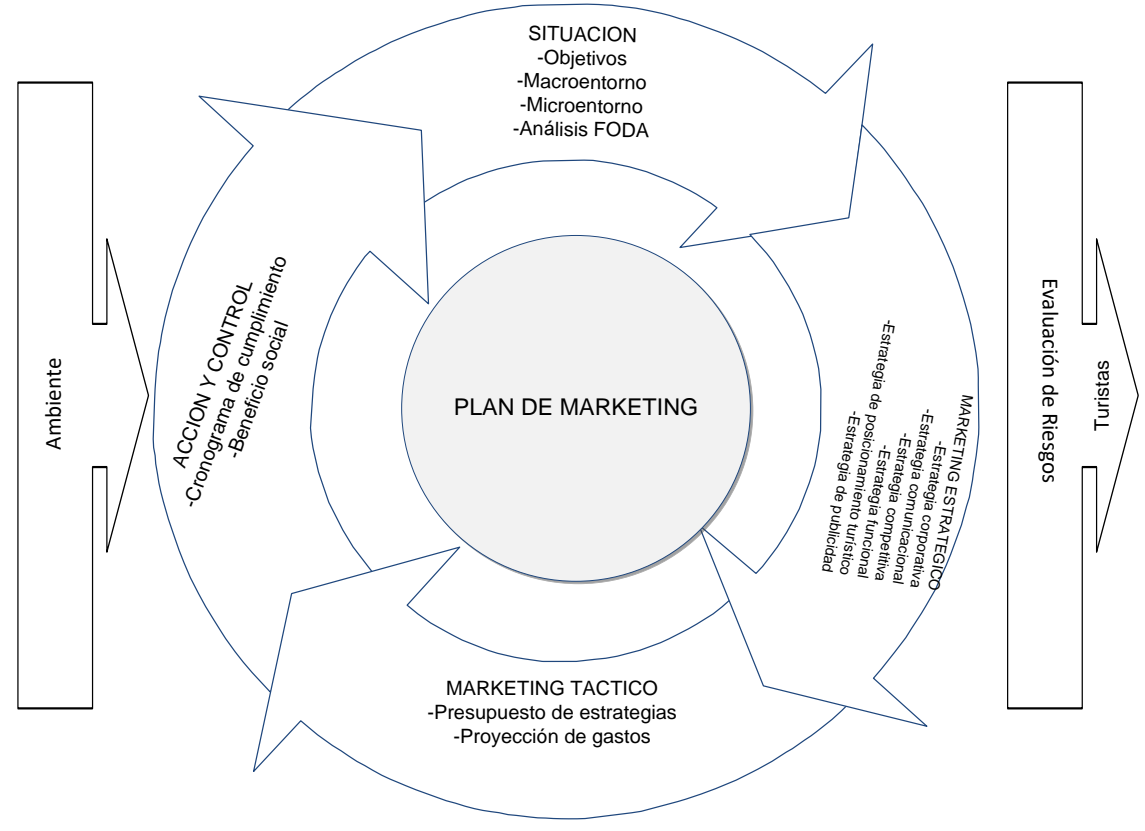

Figura 1. Representación gráfica de la propuesta de Plan de Marketing para cantón Nabón. Fuente: Elaboración propia

\section{Situación: Análisis del macro y microentorno.}

Para determinar el contexto situacional en el cual se enmarca el cantón Nabón, es necesario examinar factores políticos - legales, económicos, sociales y tecnológicos (Economía y Empresa, 2013), tal como se presenta a continuación:

\section{Factores políticos- legales}

Uno de los objetivos y deberes fundamentales que tiene el Estado ecuatoriano, está explicitado en el artículo tercero, numeral seis de la Constitución, donde se enfatiza "promover el desarrollo equitativo y solidario de todo el territorio, mediante el fortalecimiento del proceso de autonomías y descentralización" (Gobierno Nacional, 2008, p. 17).

Específicamente, el cantón Nabón, atendiendo a lo dispuesto en la Constitución Política de la República del Ecuador y en el Plan Nacional de Desarrollo, ejerce sus funciones como gobierno autónomo descentralizado, determinando para ello "políticas, programas y proyectos públicos; la programación y ejecución del presupuesto del Estado; y la inversión y la asignación de los recursos públicos" (Gobierno Nacional, 2008, p. 137; Secretaría Nacional de Planificación y Desarrollo, 2017), en coordinación con los dictámenes que le competen solamente al Estado central. En referencia al desarrollo turístico del cantón Nabón y según las disposiciones del Código Orgánico de Organización Territorial, Autonomía y Descentralización (COOTAD) en su artículo 54, epígrafe g, el GAD Municipal presenta como funciones principales: 
Regular, controlar y promover el desarrollo de la actividad turística cantonal en coordinación con los demás gobiernos autónomos descentralizados, promoviendo especialmente la creación y funcionamiento de organizaciones asociativas y empresas comunitarias de turismo. (Gobierno Nacional, 2015, p. 36)

En este sentido, al artículo 135 del mismo documento, en el párrafo sexto indica, que "el turismo es una actividad productiva que puede ser gestionada concurrentemente por todos los niveles de gobierno" (Gobierno Nacional, 2015, p. 77). Por lo tanto, es competencia del GAD Municipal del cantón Nabón acometer las acciones pertinentes para potenciar el desarrollo del turismo en esta región.

\section{Factores económicos}

Ecuador, durante varios períodos, ha generado cambios notorios en ciertos aspectos económicos. Hecho significativo ocurrió en el año 2000, donde:

Se decidió optar de manera oficial por la dolarización para sortear la crisis económica que se había gestado. Esta alternativa no sólo implica una modificación del régimen cambiario, sino se sustenta en tres pilares: cambio del sistema monetario; promoción del equilibrio macroeconómico y puesta en práctica reformas estructurales. (BCE, 2011, p. 7)

En otro orden de ideas, la inflación, a raíz de este proceso de dolarización en el país, ha bajado considerablemente a valores de un solo dígito porcentual, alcanzándose hasta el 2018 un nivel de $-0.71 \%$. Este nivel de inflación se calcula a través del Índice de Precios al Consumidor del Área Urbana (IPCU) y según "la canasta de bienes y servicios demandados por los consumidores de estratos medios y bajos, establecida a través de una encuesta de hogares" (Banco Central del Ecuador, 2016). En comparación con períodos precedentes, la inflación sigue disminuyendo ostensiblemente (Banco Central del Ecuador, 2018).

En el caso específico del cantón Nabón, se puede mencionar que la principal actividad económica de su población es la agricultura, destacándose la crianza de animales menores y la ganadería (GAD Municipal Cantón Nabón, 2018). Asimismo, el Gobierno Autónomo Descentralizado Municipal Nabón, mediante el consejo cantonal, aprobó hace 12 años la ordenanza que regula la marca territorial denominada "Nabón Productos Limpios", la cual normaliza la no utilización de químicos agropecuarios, de tal manera que la producción se caracteriza como agroecológica (GAD Municipal Cantón Nabón, 2018). Además, en la región también destacan actividades de carácter comercial, artesanal, turística y de servicio.

Las actividades que más inciden en el VAB del cantón Nabón, se corresponden con las primarias tales como la agricultura, ganadería, silvicultura y pesca, para un $32.55 \%$, en 
contraposición a las actividades de alojamiento y comida, representando estas solamente un $0.21 \%$, lo cual afecta directamente al sector turístico de la región.

\section{Factores sociales}

Específicamente en el cantón Nabón, como se ha mencionado previamente, su población 15892 habitantes (INEC, 2010), con un crecimiento promedio anual del 0.6\%, lo cual resulta bajo, en comparación con el crecimiento de la provincial del Azuay, considerándose que esta situación está dada principalmente a la migración de la mayoría de los residentes del cantón que se encuentran en edad productiva a otras regiones (GAD Municipal Cantón Nabón, 2014).

En el cantón Nabón, sucede que el 57.6\% de los hogares presentan condiciones inadecuadas, al ser deficiente sus materiales de construcción, mientras que el empleo, en correspondencia con los grupos étnicos, no demuestra diferencias significativas, por lo que los índices de población activa e inactiva, así como las personas con trabajo y aquellas desocupadas, presentan porcentajes semejantes (GAD Municipal Cantón Nabón, 2014): Se infiere que: El cantón Nabón presenta serias dificultades en cuanto al empleo, a la salud, al alcantarillado, a la vivienda y en menor medida a la educación y a la dependencia económica del hogar. Las diferencias entre la parte urbana y rural son evidentes en cuanto a la dotación de servicios básicos. (GAD Municipal Cantón Nabón, 2014, p. 101)

\section{Factores tecnológicos.}

Ecuador fue ubicada en el lugar 108 de una lista de 138 países con respecto a su capacidad demostrada para desarrollar y en cuanto a la capacidad de desarrollar y aprovechar las tecnologías de la información y las comunicaciones, según estudios emitido por el Global Information Technology Report (GITR) (El Telégrafo, 2014), evidenciándose ciertas diferencias significativas en relación al uso de las tecnologías en las zonas urbanas con respecto a las rurales.

En cuanto a la telefonía, para el mismo período de cinco años se incrementó el uso de la telefonía celular y fija donde " 9 de cada 10 hogares en el país poseen al menos un teléfono celular, 8,4 puntos más que lo registrado en el 201" (INEC, 2016, p. 6).

En cuanto a los factores tecnológicos que apenas el 7,68\% de hogares disponen de un computador y solo el 1,3\% de internet, así la cobertura de servicio de internet está más bien ligada a la localización de escuelas que imparten educación básica" No se cuenta con una radioemisora local que permita la difusión de lo ocurrido en el territorio. La señal de televisión en todo el cantón es pobre y ocasionalmente inexistente debido a las características del relieve del territorio, que dispersa las ondas de transmisión. (GAD Municipal Cantón Nabón, 2014, p. 103)

Con respecto a la red de telefonía celular, la mayoría de la región posee señal, por lo que el 59\% de los hogares tienen acceso a celular; en cambio, el servicio de telefonía fija 
presenta mayor cobertura en el área que hace parte de la cabecera cantonal, por lo que las comunidades acceden a estos servicios pero en forma limitada, para solo el 12,29\% de los hogares de las mismas (GAD Municipal Cantón Nabón, 2014). El análisis del microentorno del cantón Nabón se realiza a través de la determinación de las fuerzas de Porter, donde se identifican los diferentes factores que pueden afectar la competitividad del cantón Nabón desde diferentes perspectivas.

\section{Rivalidad entre los competidores existentes}

La provincia del Azuay está compuesta por 15 cantones, entre los que sobresalen por su actividad en materia de turismo aquellos que se mencionan a continuación: Cuenca, Gualaceo, Paute, Girón.

Estos cantones son reconocidos por el atractivo turístico que presentan, ya que poseen una amplia y hermosa biodiversidad, así como complejos arqueológicos, parques y paisajes naturales, balnearios y otros lugares pertenecientes tanto a las zonas urbanas como a las ciudades, lo que hace que dichos cantones sean preferidos para recibir visitas de turistas nacionales y extranjeros. Por lo tanto, esta fuerza se considera que tiene un alto impacto en el cantón Nabón.

\section{Amenaza de nuevos competidores}

A nivel de Provincia, el gobierno del Azuay se encuentra fomentando el desarrollo económico territorial mediante el impulso del turismo, donde los emprendedores que se encuentran en los cantones Paute, Guachapala y Sevilla de Oro, aprovechan los beneficios generados por los proyectos de infraestructura -embalses, Complejo Hidroeléctrico Paute, construcción de vías de acceso, entre otros- para, precisamente así, aprovechar el potencial natural de la zona (Castillo, 2018). Es por ello que la fuerza referente a la amenaza de los nuevos competidores para el cantón Nabón es alta.

\section{Poder de negociación de los clientes y de los proveedores}

Los visitantes o clientes del cantón Nabón son turistas nacionales y extranjeros, pero, al existir varias zonas atractivas para la actividad turística en el territorio provincial del Azuay, estos poseen diferentes opciones que pueden ser fuertemente competitivas para la región objeto de estudio, por lo que la fuerza de negociación de los clientes es alta.

Los proveedores en relación a la oferta turística desarrollada en el cantón Nabón, son las entidades gubernamentales, principalmente el Ministerio del Turismo y el Gobierno Provincial del Azuay. En el primer caso, el Ministerio del Turismo se encarga de la actividad de promoción de los principales lugares turísticos del país, dentro de los cuales no está considerado el cantón Nabón, por lo que tal situación afecta el desarrollo turístico regional. No obstante, este hecho lo contrarresta las recientes decisiones en materia de turismo que ha adoptado el Gobierno Provincial del Azuay, donde se promueve la visita de turistas a cantones menos conocidos, lo que beneficia significativamente al cantón Nabón, por lo que, de modo general, el poder de negociación de los proveedores es medio. 


\section{Amenazas de sustitutos}

Los productos/servicios sustitutivos de la oferta turística del cantón Nabón pueden ser considerados aquellos que se encuentran en zonas aledañas a la región estudiada, ya que los clientes pueden acceder a los servicios ofertados por los cantones Oña, Parte Girón, Santa Isabel o Sígsig, aunque en las regiones antes mencionadas, todavía no existe un desarrollo turístico fuerte, por lo que esta fuerza se considera como débil.

\section{Análisis FODA}

\section{Identificación de factores internos y externos}

Una vez determinados el macro y micro entorno existente para el GAD Municipal del cantón Nabón, se procede a realizar el análisis FODA, donde se determinan tanto las fortalezas y debilidades como las oportunidades y amenazas. Para así establecer el direccionamiento estratégico necesario para la organización.

A continuación, se expone la matriz estratégica, que es un instrumento de ajuste importante resultado de la combinación de los factores internos y los externos, de manera que se obtienen cuatro estrategias fundamentales, tal como se presenta en la tabla siguiente:

Tabla 2. Matriz estratégica del cantón Nabón.

\begin{tabular}{|c|c|c|c|}
\hline \multicolumn{2}{|r|}{ Fortalezas } & \multicolumn{2}{|r|}{ Debilidades } \\
\hline $\mathrm{F} 1$ & Amplia biodiversidad y recursos naturales & D1 & $\begin{array}{l}\text { Insuficiente capacidad estructural para el desarrollo } \\
\text { turístico en el cantón (hoteles, restaurantes, entre } \\
\text { otros) }\end{array}$ \\
\hline $\mathrm{F} 2$ & Movimientos culturales significativos & D2 & $\begin{array}{l}\text { Deficiencias en el proceso de comunicación } \\
\text { existente entre el gobierno y los habitantes del } \\
\text { cantón }\end{array}$ \\
\hline F3 & Experiencia en una oferta gastronómica autóctona & D3 & $\begin{array}{l}\text { Insuficiente preparación de la población cantonal } \\
\text { sobre las posibilidades y acciones a acometer para } \\
\text { el desarrollo turístico en la región }\end{array}$ \\
\hline $\mathrm{F} 4$ & $\begin{array}{l}\text { Potencialidades de diversos sectores de la población del } \\
\text { cantón para desarrollar emprendimientos turísticos }\end{array}$ & D4 & $\begin{array}{l}\text { Poca publicidad y promoción sobre los atractivos } \\
\text { turísticos que posee el cantón }\end{array}$ \\
\hline F5 & $\begin{array}{l}\text { Mejoramiento de las condiciones de acceso y } \\
\text { señalización de las vías que conducen al cantón }\end{array}$ & D5 & $\begin{array}{l}\text { Déficit en la asignación de recursos financieros para } \\
\text { el desarrollo del turismo territorial }\end{array}$ \\
\hline F6 & $\begin{array}{l}\text { Apoyo y apuesta del GAD municipal del cantón por } \\
\text { desarrollo turístico del territorio }\end{array}$ & D6 & $\begin{array}{l}\text { Falta de un plan de marketing turístico para el } \\
\text { cantón }\end{array}$ \\
\hline \multicolumn{2}{|r|}{ Oportunidades } & \multicolumn{2}{|r|}{ Amenazas } \\
\hline O1 & $\begin{array}{l}\text { Apoyo del Ministerio del Turismo para desarrollar el } \\
\text { turismo en todas las regiones del país }\end{array}$ & A1 & $\begin{array}{l}\text { Inestabilidad política que genere desconfianza para } \\
\text { lograr fomentar la inversión en las regiones }\end{array}$ \\
\hline $\mathrm{O} 2$ & $\begin{array}{l}\text { Aumento del número de visitantes nacionales y } \\
\text { extranjeros a las regiones del país }\end{array}$ & A2 & $\begin{array}{l}\text { Insuficiente desarrollo económico que provoque una } \\
\text { pérdida de competitividad en los niveles de la } \\
\text { industria turística }\end{array}$ \\
\hline O3 & $\begin{array}{l}\text { Integración de la provincia del Azuay y sus cantones en } \\
\text { la ruta de Spondylus }\end{array}$ & A3 & $\begin{array}{l}\text { Aumento de las presiones tributarias que pudieran } \\
\text { incidir en la disminución de los índices de } \\
\text { rentabilidad de los operadores turísticos }\end{array}$ \\
\hline O4 & $\begin{array}{l}\text { Mayor aprovechamiento de las tecnologías de la } \\
\text { información y las comunicaciones }\end{array}$ & A4 & $\begin{array}{l}\text { Vulnerabilidades para enfrentar eventos naturales de } \\
\text { carácter catastrófico }\end{array}$ \\
\hline O5 & $\begin{array}{l}\text { Preferencia por la práctica de las diferentes modalidades } \\
\text { de turismo }\end{array}$ & A5 & $\begin{array}{l}\text { Fortalecimiento de la competencia turística en los } \\
\text { demás cantones del territorio }\end{array}$ \\
\hline O6 & $\begin{array}{l}\text { Lograr que el país llegue a convertirse en una potencia } \\
\text { de inversión en sector turístico según los parámetros } \\
\text { establecidos por la Ley Orgánica de Fomento Productivo }\end{array}$ & A6 & $\begin{array}{l}\text { Priorización para el apoyo de otros proyectos de } \\
\text { desarrollo regional con exclusión del sector turístico }\end{array}$ \\
\hline
\end{tabular}

Fuente: Elaboración propia. 


\section{Matriz de competencia}

A continuación, se expone la matriz de competencia, que es un instrumento de ajuste importante resultado de la comparación entre el objeto de estudio y sus competidores directos.

Tabla 3. Matriz de competencia

\begin{tabular}{|c|c|c|c|c|c|c|c|c|c|c|c|c|c|}
\hline \multirow{3}{*}{$\begin{array}{c}\begin{array}{c}\text { Matriz del Perfil } \\
\text { Competitivo }\end{array} \\
\text { Atributos }\end{array}$} & \multirow{2}{*}{\multicolumn{3}{|c|}{ Cantón Nabón }} & \multicolumn{10}{|c|}{ Competidores } \\
\hline & & & & \multicolumn{2}{|c|}{$\begin{array}{c}\text { Cantón } \\
\text { Girón }\end{array}$} & \multicolumn{2}{|c|}{$\begin{array}{l}\text { Cantón } \\
\text { Cuenca }\end{array}$} & \multicolumn{2}{|c|}{$\begin{array}{c}\text { Cantón } \\
\text { Gualaceo }\end{array}$} & \multicolumn{2}{|c|}{$\begin{array}{c}\text { Catón } \\
\text { Azogues }\end{array}$} & \multicolumn{2}{|c|}{$\begin{array}{l}\text { Cantón } \\
\text { Sígsig }\end{array}$} \\
\hline & Ponderado & Valor & Peso & Valor & Peso & Valor & Peso & Valor & Peso & Valor & Peso & Valor & Peso \\
\hline $\begin{array}{l}\text { Cantidad de } \\
\text { visitantes nacionales } \\
\text { y extranjeros }\end{array}$ & $15 \%$ & 2 & 0,30 & 3 & 0,45 & 4 & 0,60 & 3 & 0,45 & 4 & 0,60 & 2 & 0,30 \\
\hline Ofertas atractivas & $14 \%$ & 3 & 0,42 & 3 & 0,42 & 4 & 0,56 & 4 & 0,56 & 4 & 0,56 & 3 & 0,42 \\
\hline $\begin{array}{l}\text { Diversificación de la } \\
\text { oferta turística }\end{array}$ & $15 \%$ & 2 & 0,30 & 3 & 0,45 & 4 & 0,60 & 3 & 0,45 & 4 & 0,60 & 2 & 0,30 \\
\hline $\begin{array}{l}\text { Inversión en el } \\
\text { desarrollo turístico }\end{array}$ & $15 \%$ & 3 & 0,45 & 2 & 0,30 & 4 & 0,60 & 4 & 0,60 & 3 & 0,45 & 2 & 0,30 \\
\hline $\begin{array}{l}\text { Calidad de la oferta } \\
\text { turística }\end{array}$ & $15 \%$ & 2 & 0,30 & 4 & 0,60 & 4 & 0,60 & 4 & 0,60 & 3 & 0,45 & 2 & 0,30 \\
\hline Infraestructura & $13 \%$ & 2 & 0,26 & 4 & 0,52 & 4 & 0,52 & 3 & 0,39 & 2 & 0,26 & 2 & 0,26 \\
\hline $\begin{array}{l}\text { Acceso vial a la } \\
\text { región }\end{array}$ & $13 \%$ & 3 & 0,39 & 3 & 0,39 & 4 & 0,52 & 4 & 0,52 & 4 & 0,52 & 2 & 0,26 \\
\hline TOTAL, PUNTAJE & $100 \%$ & & 2,42 & & 3,13 & & 4,00 & & 3,57 & & 3,44 & & 2,14 \\
\hline
\end{tabular}

Fuente: Elaboración propia.

Como se puede apreciar, el cantón Nabón está posicionado por debajo de los demás cantones en cuanto a su competitividad para el desarrollo turístico territorial, superando solamente al cantón Sígsig, por lo que se deben establecer estrategias que permitan revertir esta situación negativa.

\section{Resultados}

\section{Marketing Estratégico}

\section{Estrategia corporativa}

La estrategia corporativa del cantón Nabón consiste en la definición de un plan de desarrollo turístico para el territorio basado en el marco legal y legislaciones vigentes para garantizar las inversiones en el sector (F6-A1-A2-A3), fomentando a su vez la marca "Nabón, Progreso y Pasión" como destino turístico y posicionarse así positivamente en la mente de los potenciales turistas nacionales e internacionales (F1-F2-F3-F6-O1-O2O5). Análogamente, como método para formalizar esta estrategia, será diseñado un Manual de Identidad Corporativa para el cantón Nabón donde se incluyen los elementos mencionados anteriormente.

\section{Estrategia comunicacional}

El objetivo de esta estrategia es definir el concepto de la marca corporativa institucional en base de las bondades y fortalezas de la región (D2-O1-O4-O5), tomando en cuenta su cultura, actividades socio económicas (F2-F3-O1-O2-O6), y haciendo uso efectivo de los 
canales digitales de comunicación masiva, redes sociales como Facebook, YouTube y Twitter (F1-F2-F3-O4), dando a conocer la cualidades turísticas del cantón como son: centros de esparcimiento: Jardín Botánico Municipal, Complejo deportivo, Centro Urbano Patrimonial, turismo de aventura: rutas de Down Hill, ruta de avistamiento del Cóndor Andino, senderismo de montaña, turismo productivo, así como vivenciar la producción agrícola, artesanal y microempresarial (F4-F6-O1-O3-O5-O6).

\section{Estrategia competitiva y funcional}

En relación a la estrategia competitiva, se define diseñar un plan de desarrollo turístico para el cantón Nabón fundamentado en la promoción de ofertas gastronómicas y culturales reconocidas por su diferenciación (F2-F3-O1-O2-O6) con respecto a las demás propuestas que brindan las demás regiones de la provincia del Azuay (F1-F2-F3-F6-A5A6). Como estrategia funcional, se define que, para acometer con efectividad el desafío que implica el desarrollo turístico en el cantón Nabón, será conceptualizada e implementada una estructura organizativa que satisfaga los requerimientos de gestión administrativa para el desarrollo turístico en el cantón Nabón (F6-A5-A6), la cual puede seguir el delineamiento siguiente:

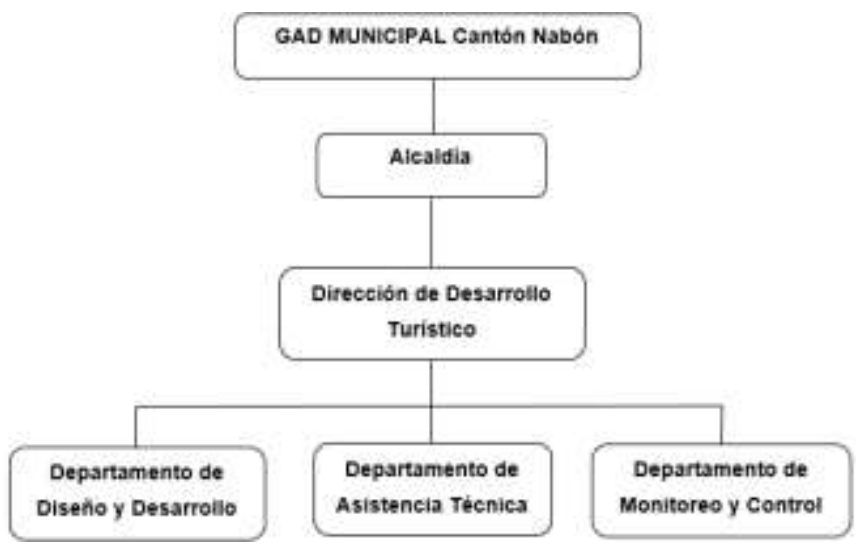

Figura 2. Estructura organizacional para el desarrollo turístico del cantón Nabón Fuente: Elaboración propia.

Seguidamente, se definen las principales funciones de cada departamento que conforman la Dirección de Desarrollo Turístico para el cantón Nabón:

\section{Dirección de Desarrollo Turístico}

Su principal misión consistirá en promover y asegurar el desarrollo turístico del cantón Nabón a través de la implementación de un plan estratégico, estableciendo pautas y el direccionamiento estratégico que posibilitará cumplir con la misión y contribuir al progreso del territorio desde las perspectivas sociales y económicas.

\section{Departamento de Diseño y Desarrollo}

Fomentar el turismo como una práctica económica alternativa y sustentable que favorece al mejoramiento de la calidad de vida de la población de la región en el contexto social, 
económico y cultural, determinando los requisitos esenciales para promover el fortalecimiento turístico. Entre sus funciones fundamentales se mencionan:

- Impulsar y desarrollar la industria turística en la región en correspondencia con el marco legal y legislaciones vigentes al respecto.

- Optimizar y asignar apropiadamente los recursos para asegurar el correcto proceso inversionista para el desarrollo del turismo en el cantón Nabón.

- Apoyar programas de capacitación entre la población del cantón Nabón en beneficio del desarrollo turístico.

- Desarrollar acciones para lograr el mejoramiento de la infraestructura del cantón Nabón y aumentar así sus niveles de competitividad en la industria turística.

- Colaborar con los operadores turísticos existentes en la región para promover la práctica del turismo con altos estándares de calidad y seguridad.

\section{Departamento de Asistencia Técnica:}

Promover entre los distintos grupos de interés que intervienen en el desarrollo turístico de la región la materialización del plan estratégico diseñado en este sentido, a través de la gestión adecuada de los recursos, calidad del servicio, capacitación del talento humano y desarrollo de la infraestructura. Entre sus funciones fundamentales se mencionan:

- Impulsar la creación de emprendimientos en la industria turística caracterizados por su alto nivel de competitividad y organización.

- Instruir a los operadores turísticos para que estos alcancen el financiamiento adecuado y puedan cumplir con sus funciones para el cumplimiento de los requerimientos de los clientes.

- Establecer procesos de capacitación y adiestramiento para los habitantes del territorio en cuestiones de emprendimiento, administración en la rama del turismo, entre otros.

- Apoyar a las empresas turísticas que ofrecen productos y servicios distintivos, de manera que estas generen un mayor valor para los visitantes a la región.

\section{Departamento de Monitoreo y Control:}

Impulsar el desarrollo del turismo en el cantón a través del monitoreo y control de las actividades relacionadas, para informar periódicamente a las partes interesadas (instituciones públicas, empresas y población) acerca del cumplimiento de las metas trazadas, además de establecer un proceso de retroalimentación que permita delimitar medidas de ajuste pertinentes en los casos que sea necesario. Para ello:

- Se conformará una Junta de Monitoreo y Control para el Desarrollo Turístico,

- Realizar señalamientos al diseño e implementación de los planes de desarrollo turístico en la región.

- Planear, organizar y desarrollar un seguimiento a la gestión de los planes de desarrollo turístico en el territorio.

- Conformar eventos para discutir sobre los temas que pueden afectar o beneficiar el desarrollo turístico en la región. 


\section{Estrategia de posicionamiento turístico}

Como estrategia de posicionamiento turístico, se plantea establecer plazas para el fomento del turismo para cantón Nabón, para lograr atraer y asimilar la cantidad de visitantes al mismo (D1-D5-O1-O2), lo que facilita la inversión para el desarrollo del sector turístico la región (F4-F6-O1-O3-O5-O6). Para ello, se propone realizar estudios técnicos para determinar la factibilidad de la modificación y reconstrucción de un recinto que facilite los intercambios culturales entre los pobladores y los visitantes al cantón.

Además, en dicho lugar se colocará un stand para ofrecer información relevante acerca del atractivo turístico que reviste el cantón Nabón, por encontrarse ubicado este local en un lugar sumamente estratégico y accesible (carretera Panamericana), precisamente en la vía de entrada al cantón.

\section{Estrategia de publicidad}

Promocionar el desarrollo turístico del cantón Nabón a través de la utilización de las tecnologías de la información y las comunicaciones (F1-F2-F3-O4) y demás medios tradicionales, de manera que se logre posicionar la marca "Nabón, Progreso y Pasión" en la mente de los visitantes nacionales y extranjeros para lograr aumentar su preferencia del territorio como destino turístico (F1-F2-F3-F6-O1-O2-O5), optimizando y asignando apropiadamente los recursos necesarios para acometer con efectividad dichas acciones (D4-D5-O1-O4-O6). Son amplias las acciones a desarrollar en cuestiones de publicidad del cantón Nabón, entre las que se encuentran:

- Diseños publicitarios en vallas donde se publicite al cantón Nabón desde tres perspectivas diferentes: el atractivo de los productos naturales que se comercializan en la región, la práctica del turismo de aventura y la gastronomía autóctona del territorio.

- Diseños publicitarios para los buses de transporte público que circulan en el cantón Nabón, como método efectivo de posicionamiento de marca en la mente de los visitantes.

- Diseño y construcción de tres stands publicitarios, los cuales serán ubicados en lugares de alta concurrencia de personas, tales como el aeropuerto de Cuenca, el Mall del Río y el recinto cultural a construir mencionado anteriormente.

- Diseño y construcción de Centro de Información, cuya ubicación será el recinto cultural a construir mencionado anteriormente, donde será proporcionada información relevante sobre las bondades turísticas que ofrece el cantón Nabón.

- Utilizar los medios publicitarios existentes en plataformas virtuales, tales como las redes sociales y el sitio web del cantón Morona, donde se publicarán videos de la región, historias o casos de éxito (donde se exponen experiencias positivas de los visitantes al cantón) para obtener mejores resultados de posicionamiento y ofrecer a los usuarios información concisa acerca de los atractivos turísticos del territorio. El diseño de estos elementos publicitarios fue reflejado en la estrategia corporativa.

\section{Marketing táctico}

El marketing táctico se fundamenta en la disgregación de las acciones empleadas para el cumplimiento de las estrategias, Asimismo, la inversión para el desarrollo de las acciones 
también es definida, por tanto, se presupuesta el Plan de Marketing para el desarrollo de la provincia del Azuay.

\section{Acción y Control}

La acción y control del Plan de Marketing propuesto para el cantón Nabón está fundamentada en el cronograma para la ejecución del mismo.

\section{Conclusiones.}

- En virtud que el Plan de Marketing liderado por el GAD Municipal del cantón Nabón. La cual presenta la capacidad financiera para materializar las estrategias y tácticas descritas previamente. No obstante, los beneficios derivados, más que valores de rentabilidad, se encuentra asociados a una perspectiva social, ya que su impacto en la población de la región donde se encuentra comprendido el cantón es altamente significativo, debido a varios factores.

- La implementación del Plan de Marketing estratégico implica la generación de una imagen de marca positiva sobre el cantón Nabón, presentando los atractivos turísticos y las potencialidades del territorio en cuanto a su diversidad cultural y su gastronomía autóctona, derivando una mayor atracción de visitantes nacionales y extranjeros, por lo que resulta imperante la creación de nuevos emprendimientos de servicios e infraestructura que permitan responder a la demanda creciente al respecto.

- Todo ello supondría la necesidad de creación de nuevos empleos, así como se evitaría de forma implícita la migración de la población del cantón Nabón hacia otras regiones de la provincia del Azuay u otros territorios, contribuyendo estos a su desarrollo económico.

- Y finalmente, este nuevo escenario conduce a transformaciones en el ámbito educativo y tecnológico, relacionados con la gestión turística por parte de los diferentes grupos de interés (proveedores del servicio, población cantonal, entre otros) para así lograr cumplir con los objetivos y las metas estratégicas que posibiliten un mayor desarrollo turístico.

\section{Referencias Bibliográficas.}

Armijo, M. (2011). Planificación Estratégica e indicadores de desempeño en el sector público. Santiago de Chile: Cepal.

Artesi, L. (2002). Turismo, desarrollo local y redes. Aportes y transferencias, Universidad Nacional de la Patagonia Austral, 71-92. 
Banco Central del Ecuador. (2016). Estadística Banco Central del Ecuador. Quito: BCE. Obtenido de https://www.bce.fin.ec/index.php/component/k2/item/156preguntas-frecuentes-banco-central-del-ecuador

Banco Central del Ecuador. (14 de junio de 2018). Obtenido de Banco Central del Ecuador: https://contenido.bce.fin.ec/resumen_ticker.php?ticker_value=inflacion

BCE. (2011). La dolarización en el Ecuador. Quito: Banco Central del Ecuador.

Buil, I., Melero, I., y Montaner, T. (2012). La estrategia de marketing con causa: Factores determinantes de su éxito. Universia Business Review (36), 90-107.

Burbano, F. (2013). Antología, democracia, gobernabilidad y cultura política. Quito: FLACSO. Sede Ecuador.

Bustamante, F. (2016). La cultura política y ciudadanía en el Ecuador. Quito: CORDESPNUD.

Cantillo, E. (2013). Factores claves en la gestión de mercadeo que inciden en la competitividad del sector de comunicaciones gráficas de la ciudad de Barranquilla, Colombia. Revista Escuela de Administración de Negocios, 75, 142151.

Carballo, R., Moreno, S., León, C., y Brent, J. (2015). La creación y promoción de experiencias en un destino turístico. Un análisis de la investigación y necesidades de actuación. Cuadernos de Turismo, 35, 71-94.

Castillo, M., y Castaño, V. (2015). La promoción turística a través de técnicas tradicionales y nuevas. Estudios y Perspectivas en Turismo, 737-757.

Castillo, N. (2018, octubre 19). El turismo despunta en tres cantones azuayos. El Comercio, pp. 4-5.

Chuquimarca, J. (2013). División de poderes en la actual Constitución del Ecuador. Resistencia, 50-52.

Cueva, R. A. (1999). Marketing; enfoque América Latina. Mexico: McGraw Hill.

Echeverri, L. (2009). Marketing práctico: una visión estratégica de un plan de marketing. Madrid: Starbook Editorial.

Economía y Empresa. (2013). El análisis PESTEL: Asegure la continuidad de su negocio. 2016: 50Minutos.es.

El Telégrafo. (10 de noviembre de 2013). La pobreza en Ecuador se reduce y la riqueza se redistribuye. El Telégrafo, 2-4.

El Telégrafo. (6 de octubre de 2014). Banco Mundial: El crecimiento ha sido inclusivo. El Telégrafo, p.2. 
El Telégrafo. (2014, abril 23). Indicadores de las TIC de Ecuador con Relación a los Países. El telégrafo, p. 14. Retrieved from https://www.eltelegrafo.com.ec/noticias/tecnologia/1/ecuador-escala-9-puestosen-ranking-de-aplicacion-de-las-tic

Falconi, F. (2013). Dolarización y desdolarización. Íconos, 22-24.

GAD Municipal Cantón Nabón. (2014). Plan de Ordenamiento Territorial del cantón Nabón. Diagnóstico integrado. Cuenca: PYDLOS/Universidad de Cuenca.

GAD Municipal Cantón Nabón. (2018, enero 24). Gobierno Autónomo Descentralizado Municipal Cantón Nabón. Retrieved from GAD Municipal Cantón Nabón: http://www.nabon.gob.ec/datos-del-canton/\#1523640018226-74bf08fb-7866

Gobierno Nacional. (2008). Constitución de la República de Ecuador. Quito: Asamblea Nacional.

Gobierno Nacional. (2015). Código Orgánico de Organización Territorial, Autonomía y Descentralización (COOTAD). Quito: Gobierno Nacional.

INEC. (2010). Censo de Población y Vivienda. Quito: Gobierno Nacional.

INEC. (2016). Tecnologías de la Información y las comunicaciones (TIC’S) 2016. Quito: INEC.

INEC. (2018). Boletín Técnico IPC No. 06-2018. Quito: INEC.

Kotler, P., y Amstrong, L. (2017). Fundamentos de Marketing. México D.F.: Pearson Educación.

Kotler, P., y Keller, K. (2012). Dirección de marketing. México D.F.: Pearson Educación.

Kottler, P. (2011). Marketing turístico. Madrid: Pearson Educación.

Martínez, D. (2016). Factores clave en marketing: enfoque de empresas de servicios. Orbis. Revista Científica Ciencias Humanas, 12(34), 42-58.

Méndez, G., Augusto, A., y Gándara, J. (2013). Innovación en la promoción turística en medios y redes sociales. Un estudio. Estudios y Perspectivas en Turismo, 22(1), 103-119.

Muñiz, N., y Cervantes, M. (2010). Marketing de ciudades y "Place Branding". Revista de la Facultad de ciencias Económicas y Empresariales, 123-149.

Pascual, P., Santos, M., y López, J. (2014). Factores determinantes en el éxito del desarrollo del nuevo servicio. Tourism \& Management Studies, 10(2), 67-74.

Paz y Miño, J. (2016). La crisis bancaria de 1999: el retorno de la plutocracia. Historia y economía, 1-21. 
Secretaría Nacional de Planificación y Desarrollo. (2017). Plan Nacional de Desarrollo 2017-2021. Toda una Vida. Quito: Secretaría Nacional de Planificación y Desarrollo - Senplades.

Segura, S. (2015). El aporte de la actividad turística y el ingreso de divisas para el Ecuador. Revista Empresarial, ICE-FEE-UCSG, 35-43. 


\section{Para citar el artículo indexado.}

Idrovo E., Luna K., Ordoñez J. \& Lituma M. (2019). Marketing estratégico turístico para la Provincia del Azuay-Ecuador. Revista electrónica Visionario Digital 3(2), 213-. Recuperado desde: http://www.cienciadigital.org/revistascienciadigital/index.php/VisionarioDigital/article/ view/408/928

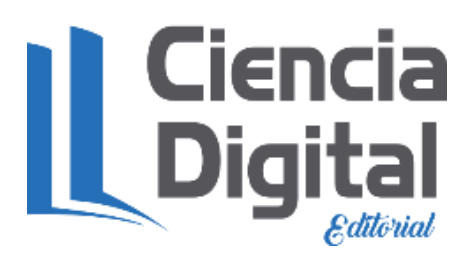

El artículo que se publica es de exclusiva responsabilidad de los autores y no necesariamente reflejan el pensamiento de la Revista Ciencia Digital.

El articulo queda en propiedad de la revista y, por tanto, su publicación parcial y/o total en otro medio tiene que ser autorizado por el director de la Revista Ciencia Digital.
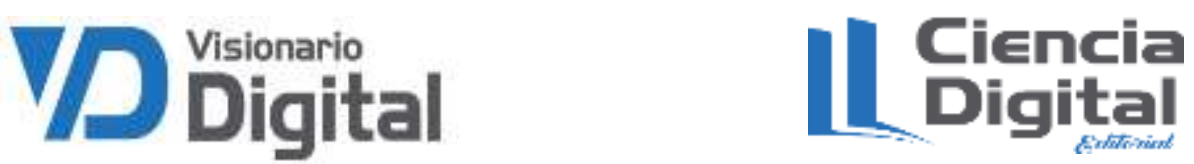